\title{
14. Socially Engaged Theatre and Performance in Italy: Politics, Ethics and Aesthetics
}

\author{
Fabrizio Fiaschini and Roberta Gandolfi ${ }^{61}$ \\ doi.org/10.3280/oa-637-14
}

\section{The Legacy of the Sixties}

In historico-critical terms, the relationship between aesthetics and ethics in performance and social theatre in Italy can be exemplified by the publication, between 1968 and 1969, of the Italian editions of Antonin Artaud's Le théatre et son double (1938) and Walter Benjamin's Programm eines proletarischen Kindertheaters (1969).

What these two powerfully visionary and heterodox texts have in common is, above all, the emergence of the performative device, highlighted by the body-action synthesis: the core of an anti-narrative and anti-representative artistic process, brought back to the ground zero of a non-specialised cultural action, which goes beyond the closed, self-referential forms of the mainstream theatre. In this perspective, the performative device feeds a widespread creativity, with a socio-anthropological matrix, capable of influencing the transformations of the political system, without ever indulging in instrumental and functionalist ideological drifts.

Within this scenario, the revolutionary path indicated by Artaud is one of desecratory cruelty, of a regressive and painful aesthetics of the body, heading in the direction of the synthesis of body and mind. This indissoluble unity of thought and action, represents, for Artaud, the original source of a lost organicity, and of an affective athleticism made of poetry, flesh and breath, oriented more towards life than towards art, for the regeneration of the human being and consequently of society (Ruffini, 1996 and 2000; Cambria, 2001 and 2007; De Marinis, 2006).

The other path, traced by Benjamin together with director Asja Lacis, privileges the ludic aspect of theatre, conceived as a non-imitative practice of incorporation of reality, of deconstruction and recomposition of the world. It is a work of improvisation, freed from aesthetic, political and social aims, whose results take shape in the unfinished articulation of the childish gesture,

61 This essay was conceived together by the authors; the writing was divided as follows: paragraph 1 was written by Fabrizio Fiaschini, paragraph 2 by Roberta Gandolfi. 
becoming a «secret signal» of a future awaiting completion (Fiaschini, 2019).

Prompted by these two visions of performance, the Italian Protest Theatre gave life, between the end of the 1960s and the early 1970s, to some of its most original and innovative experiences.

Simplifying a little, one could say that the Artaudian line fed the developments of what goes under the name of New Theatre: a differentiated and multiform phenomenon based on the experimentation of laboratory theatre and on stage writing (De Marinis, 1983; Mango, 2003; Schino, 2009; Margiotta, 2013; Acca, 2019). These two devices similarly overcame the concept of work of art as a product heading towards an open and not aesthetically programmed process, which was connoted as research on the essence and identity of what is human, starting from the transformative and regenerative value of the synthesis body-action, where body meant both the individual body and the social body. In this perspective, the New Theatre was conceived, internally, as the turning point of an aesthetic (re)foundation of a new theatrical language, and, externally, as a form of cultural-political militancy, aimed at reconfiguring the mechanisms of theatrical production, organisation and communication. The theatrical profession thus ended up encompassing the artist, the cultural operator, the political activist and the militant critic in a single profile. The individualised and specialist approach to culture was replaced by group culture, understood both as a self-managed model of cooperation and as an artistic practice of collective writing, open to the participation of the spectator and the involvement of the community. This activist thrust was artistically interpreted by the community-based groups and the research theatre by activating all the possibilities of the performative device, such as site-specific art, installation, happening and environmental theatre. A widespread contamination of theatrical practices that aimed to regenerate urban spaces of social interaction or reinvented itself in the nomadic forms of itinerancy.

Next to the intense projectuality of the New Theatre, the line inspired by Benjamin fed instead the other strand of the 1968 protest: that of the so-called Animazione teatrale ${ }^{62}$, probably the most eccentric and transgressive proposal of those years, certainly the closest to contemporary socially engaged theatre experiences (Scabia and Casini Ropa, 1978; Perissinotto, 2004; Fiaschini, 2015). Not entirely satisfied with adopting the principles and languages of laboratory theatre and stage writing, the Animazione teatrale was in fact the most explicit example of aesthetic "profanation",

${ }^{62}$ For an explanation of the meaning of Animazione teatrale see the Notes on Translations on p. 7. The expression is used in this sense throughout the paper. 
aimed as it was at restoring creative potential to common and amateur use, undoing the double link between art and professionalism that had separated ("sacralised") and made this very potential unavailable, even in its most avant-garde forms.

It is no coincidence that the term itself, Animazione teatrale, underlines the idea of nourishing a theatricality that animates everyone, indiscriminately, before and beyond any artistic convention, technicality and professional specialisation.

In this respect, the line of the Animazione teatrale not only embraced the antagonistic positions, extremely critical towards the capitalist model of artwork's commodification, but also fully recovered the ludic meaning of theatre evoked by Benjamin. In the practices of Animazione teatrale, the primacy of play, in fact, brought the theatrical action back to a performative level which, in its gratuitousness and social shareability, was freed from any subordination to professionalism, as well as from any aesthetic constraint between the performative action and its purpose. The play-space released by the Animazione teatrale device restored the theatre to its original status of «means without end»: that is, paraphrasing philosopher Giorgio Agamben, of aesthetic practice which, while maintaining the instrumental nature of the medium, was not obligated to any predetermined end (Agamben, 1996 and 2005). The result, borrowing Bartolucci's words, takes the form of a «horizontal dramatisation» (Bartolucci, 1973, p. 30 and 1976, p. 11), which is at the same time the aesthetic sign of a non-artistically formalised beauty and the political sign of a change that was not ideologically programmed. In other words, the performative actions of the Animazione teatrale testify to the chance of an aesthetic of community action, favouring the reappropriation, by the choir-group, of its own imaginary and resources in terms of socialisation and change (Dalla Palma, 1971).

The aesthetic revolution of the ludic paradigm was moreover reinforced by the close alliance between Animazione teatrale and alternative pedagogy the latter particularly supported by the school reform movements, such as the Movimento di Cooperazione Educativa (MCE, Italian Educational Cooperation Movement) inspired by Célestin Freinet (Alfieri, 1974) based on the principle of free expression of speech, body and gesture.

Notable among the protagonists of this short but intense season is Giuliano Scabia (Marchiori, 2005; Casi, 2012). Between 1969 and 1970, within the theatrical decentralisation project promoted by the Teatro Stabile di Torino, he carried out a set of community performative actions in the suburbs of the city, aimed at giving voice and political visibility to struggles of FIAT workers (Scabia, 1973). Performances involved the entire neighbourhood, the workers' families and especially the children in a process of improvisation and 
collective writing based on the assembling of heterogeneous materials (audio recordings, newspaper articles, photographs, video documentaries, signs, puppets). In the same context, Scabia also tested his "empty scheme": an educational and social dramaturgy open to the free composition of the participants, later reproposed in 1971 with the children of the school of Sissa and merged in a series of performative dramatisations dedicated to themes chosen daily by the children themselves (Bartolucci, 1972).

Scabia was also the creator and director of one of the first projects of socially engaged theatre in the context of mental illness, in collaboration with the antipsychiatry movements that in 1978 led to the introduction of the so-called Basaglia Law and the closure of psychiatric hospitals. Inside the Trieste asylum, Scabia ran an open laboratory of collective creativity and political reflection which led to the multiplication of artistic codes and languages (painting, puppets theatre, singing, scenic actions) and ultimately resulted in the creation of Marco Cavallo. This was a large blue papier-mâché horse, which was taken out of the asylum after knocking down the narrow door of the room containing it and was paraded through the streets of the city of Trieste: an overwhelming performative gesture, which for everyone involved (patients, educators, artists, actors, psychiatrists, citizens) became a living metaphor of a freedom unexpectedly rediscovered in the great urban theatre of the collective feast, regardless of any artistic or ideological finalisation (Scabia, 1976).

From the second half of the 1970s, the aesthetic utopia of the Animazione teatrale and of some key experiences of the New Theatre underwent a marked transformation. The implosion of movementist ideals and the extremist drift of the political struggle led to a U-turn in the extroverted drive of cultural and social militancy (militant groups), towards increasingly institutionalised disciplinary boundaries, more and more formalised in artistic, productive and professional terms. This signalled an aesthetic reversal that led the research of the New Theatre to move the scenic writing back within mainstream theatre, and to dissolve it into a multiplicity of experimentations: ranging from the mental and conceptual minimalist theatre of the Post-avant-garde, to visual poetry and environmental installations, down to the re-foundation of the relationship between playtext, actor and director in a new critical perspective of staging (Valentini, 2015; Valentino, 2015).

Similarly, the most eccentric fruits of Animazione teatrale (amateurism, collective writing, contamination between artistic languages, festive dramaturgy, participatory art) were rapidly metabolised in a process of professionalisation which, although with original and innovative outcomes, returned to focus on an exclusive relationship between process and work of art. This relationship had two effects: on the socio-educational and 
therapeutic side, it tended to privilege, through the training - play improvisation paradigm, the protected process framework of the theatre-lab; on the artistic side (for example in theatre for children), it fuelled an artisticspectacular tension, which, however, almost never included direct engagement in the socio-political context (Fiaschini, 2016 and 2018a).

In this context, a new alternative to traditional theatre and research theatre should be underlined: the experience of the Third Theatre movement. Founded by Eugenio Barba in 1976 the Third Theatre aimed to bring together all the theatrical entities that were operating in marginal situations and identified themselves with a "group culture" more interested in the anthropological declinations of performance than in its aesthetic ones (Barba, 1985 and 1990). Starting from an approach of transcultural research and from the principle of daily self-training as a discipline of life, the Third Theatre thus went back to the social perspective: however, its direction was geared more towards the comparison with performance practices of other cultures (especially Asian theatres) or of traditional Italian popular culture (street theatre, festive dramaturgy, folk dances), rather than in the direction of any explicit political commitment. This is demonstrated by the fact that, from the very beginning, a fracture opened up in the Third Theatre between community-based theatre groups, which conceived this anthropologicalcultural tension as a civic commitment, and groups, more linked to the Odin Teatret, which instead understood it as the matrix of an internal work process, most often in an artistically-oriented perspective (Schino, 1996).

In order to find explicit signs of a socio-political engaged theatre again, it is necessary to wait until the beginning of the 1990s, when a wide and varied geography of theatrical and performative practices, often heterogeneous, began to emerge from below in equally numerous non-artistic contexts: from the therapeutic field to that of social marginality, from new poverty and inequality to schools, inter-cultural and migratory phenomena, down to the experiences of social theatre and urban regeneration (Pozzi and Minoia, 1999; Bernardi, Cuminetti and Dalla Palma, 2000). This galaxy of experiences is characterised mostly by spontaneous and self-determined entities, often equally alien to the theatrical research culture and to political activism. However, their strength lay precisely in the spontaneity of the peer relationships they created, reinforced by a non-predetermined theatrical approach based on the ethics of contribution: that is on the power of theatre to create value and to plan change through participatory action, in order to translate (passive) consumerism into (active) generativity.

These are the movements that characterise the constellation of "socially engaged theatre" today (Bernardi, 2004 and 2015; Rossi Ghiglione and Pagliarino, 2007; De Marinis, 2011; Fiaschini, 2013; Rossi Ghiglione, 2013; 
Pontremoli, 2015; Porcheddu, 2017). This definition is not meant to delimit a particular type of theatre (with its method and field of intervention), but, on the contrary, it underlines the a-specific character of its identity and the extreme permeability of its theoretical and methodological models of reference, as well as the heterogeneity of the experiences it has been able to generate.

In this perspective of disciplinary trespassings, during the last ten years socially engaged theatre (together with new trends in participatory art) has established itself on the national scene as one of the most innovative practices of contemporary theatre research, in both an artistic and socio-political sense. And it seems emblematic that, exactly forty years after the momentous biennium 1967-1968, the new affirmation of socially engaged theatre has been consolidated in the biennium 2007-2008, marked by the worldwide collapse of Lehman Brothers: the symbolic epilogue of the crisis of the neoliberal model based on the competitive principle of social inequality and of excellence, on the myth of individual well-being and of the mediatised aestheticisation of life. A subjectivist and privatistic drift to which socially engaged theatre has opposed a systemic relational vision of creative relationship, a collaborative approach capable of mending the fracture between individual and community, between public and private. According to socially engaged theatre principles, this can be achieved by giving voice and expression to an action in which the relationship between individual and society is no longer the result of an unbridgeable fracture between the man (the private subject) and the citizen (the public subject), but it is the outcome of a constructive interaction between the search for individual well-being and the aspiration to the common good (Fiaschini, 2018b and 2020a).

In this frame, the aesthetics of socially engaged theatre can therefore be defined as an aesthetics of care, where the word must be interpreted in its bio-psycho-social meaning of taking care of oneself and of the others in a systemic perspective of change, starting from a common act of assuming responsibility towards the world (Fiaschini, 2020b).

A solidaristic approach based, in turn, on the unconventional flipping of the idea of weakness, no longer seen as a condition limited to specific disadvantaged or marginal categories, but as evidence of a widespread fragility: a vulnerability of the individual as well as of the collective body, which concerns everyone and the ecosystem itself, making us all fundamentally helpless and therefore increasingly dependent on each other. In this scenario of vulnerability and proximity, the aesthetics of socially engaged theatre therefore attempts to capture, in the fragile sign of a performing art restored to common use, the foundations of a cultural plan which, once again, finds in a theatrical gesture that is neither artistically 
programmed nor ideologically connoted the most effective way to understand oneself and to look lucidly at the world, orienting it towards a better future.

\section{With Women's Bodies: Theatre as a Tool for the Empowerment of Collective Subjects}

The second part of this co-authored paper moves away from the field of theatre and its Italian developments (Nuovo teatro ${ }^{63}$, Animazione teatrale, social theatre) and privileges the social and political scope of the period. It takes into consideration the new subjectivities that were protagonists of the renewal of Italian society in the second half of the $20^{\text {th }}$ century, and it focuses on their agency and their recourse to performativity. Point of departure is one of the most important of the many activist movements of the 1960s and 1970s: the women's movement, whose struggles and agendas transformed the patriarchal structure of society, bringing lasting changes in European legislation and customs.

The agendas of women's movements converge symbolically with the territories of performativity: as a matter of fact, body and language have always been the two main expressive registers of theatre and performance, they were (and are) also the privileged terrain of the feminist revolution. During the second half of the $20^{\text {th }}$ century the feminist battle for selfdetermination, as it is known, started from the reappropriation of the female body, defying the normativity of motherhood as a biological destiny and of a female sexuality intended for exclusive male consumption. The feminine body needed to be freed from the specialisms of the medical discourse as well as from the objectification of women proposed by the consumerism of mass society. It is no coincidence that in 1970s Italy the practice of self-help became very popular in women's groups and in the first self-managed counselling centres that later became a public service. This trend was disseminated in Europe by the Boston Women's Health Collective thanks to a book of great accessibility, designed to be available to each and every woman, Our Bodies, Our Selves (1970).

On the other hand, gender awareness grew thanks to an extraordinary and choral attitude to speaking out adopted by women, originating from the separatist and liminal practice of consciousness-raising, based on the stance that «the personal is political» (De Lauretis, 1990; Bracke, 2014). The political practice of small groups of women who compare and discuss their

${ }^{63}$ For an explanation of the meaning of Nuovo teatro see the Notes on Translations on p. 7. The expression is used in this sense throughout the paper. 
respective oppressions by confiding in each other, was later transferred to the theoretical elaboration, with the philosophical proposal of relational paradigms that suggest mutual listening as the basis of any recognition of identity. This was very well analysed by Adriana Cavarero in her eloquently titled book Tu che mi guardi, tu che mi racconti. Filosofia della narrazione (1997; En. transl. Relating narratives. Storytelling and Selfhood, 2014). Cavarero has recently continued her philosophical elaboration with the volume Inclinazioni. Critica della rettitudine (2014; En. transl. Inclinations: a critique of rectitude, 2016) where she rethinks subjectivity in terms of inclination; she argues that the postural inclination towards the Other (the Child, in Marian iconography) has an ethical and aesthetic value, and formulates a vision akin to the paradigm of care hitherto formulated. Cavarero's postural paradigm of (female) inclination, as opposed to the classical (male) rectitude, is thus valuable for thinking the performativity of theatre in the social sphere, as well... Bodily postures, language, narration and subjectivity: it is not surprising that there is a convergence between the empowerment of female subjectivity and theatrical and performative agency...

The widespread recourse of women to corporeality and theatricality as a means of self-expression, self-discovery, communication, awareness-raising and care, beyond any specialist and professional divide, is part of a "history written from below" which remains largely unexplored. Despite having been scarcely investigated by academic research, it emerges clearly from firsthand reports and journalistic sources of the 1970s. effe, the most important Italian feminist magazine of that period, published monthly with a large circulation between 1973 and 1982, documents the use of theatre for the women's movement (Gandolfi, 2019). It bears witness to the feminist collectives who chose to adopt the languages of agit-prop and street theatre as their form of communication, privileging parody registers, while other collectives, mindful of Asja Lacis's example, committed themselves to Animazione teatrale as a form of alternative pedagogy, and engaged theatrically in the deconstruction of gender roles since early childhood. As a matter of fact, pedagogist Elena Gianini Belotti's ground-breaking study, Dalla parte delle bambine (1973), translated as Little Girls: Social Conditioning and Its Effects on the Stereotyped Role of Women During Infancy, was published in in Italy at this time. effe also mentions the Nemesiache, a Neapolitan visionary collective that theorised the choral and amateur appropriation of visual, verbal and performative creative registers as a privileged form of «feminist reinvention of the political» (Bracke, 2014); the Nemesiache committed for many years to socially engaged art with the inmates of the Frullone Psychiatric Hospital in Naples (Campese, 2019). Last 
but not least, effe documents at large the deeds of the Teatro della Maddalena (1973-1989), the most important Italian feminist theatre, founded in Rome by feminist writer and playwright Dacia Maraini with a group of fellow Roman intellectuals, journalists and actresses. From the very beginning the theatre's repertory was inclined towards socially engaged art, intertwined with feminist activism in the suburbs, the new dormitory districts that were growing up on the outskirts of Rome during those years of wild urbanisation. The feminists' aim was the redemption of the condition of suburban proletarian working women and housewives; their debut at the Maddalena, Mara Maria Marianna, adopted a medallion dramaturgy, with stage portraits of women met and interviewed in the Magliana area, employing the aesthetics of truth theatre and enquiry theatre (Stelliferi, 2015; Gandolfi, 2018; Pulga, 2020). For over fifteen years the Maddalena remained faithful to its radical ethic of making the scene accessible both for professional (theatrical women) and non-professional; such policy was the source of recurring conflicts and dropouts, but it guaranteed the collective and notspecialised exercise of creativity and the democratisation of artistic languages, in accordance with the political project of empowering the expression of women, understood as a collective social subject (Maraini and Murrali, 2013).

In the 1980s and 1990s the women's scene, in Italy as in Europe, developed several networks which provided exchange, alliances, synergies and empowerment among women in the theatre: it is worth mentioning Divina, active in Turin between 1990 and 1996 (Pedrazzoli, 2007) and the international network Magdalena Project, highly active in Italy since 1986 and linked to the Third Theatre and group theatres (Palladini, 2012), whose magazine, Open Page, made explicit from its very title its inclusive editorial policy, giving space to many professionals, several of which committed with socially engaged theatre ${ }^{64}$. Thus, the theatres with female voice developed the habit of enhancing female subjectivity and privileged dramaturgies that value life experiences and intertwine individual and collective memories. In fact, plays and workshops based on witnessing, listening and exchanging stories flourished between the old and the new millennium, co-designed with various local institutions; their diffusion was wide and proves rather difficult to map.

Two long-term experiences set at the two opposite geographical poles of Italy can be mentioned as exemplary. In the Northern industrial city of Turin, land of the great workers' struggles of the $20^{\text {th }}$ century, the Teatro Coordinamento Donne involved for ten years retired trade unionists of the SPI CGIL ${ }^{65}$ in

${ }^{64} \mathrm{https}: / / \mathrm{www}$. themagdalenaproject.org/en/content/open-page
${ }^{65} \mathrm{https} / / / \mathrm{www}$. spicgiltorino.it/project/il-teatro-del-coordinamento-donne-di-torino/ 
weaving choral memory threads concerning the political role played by women in the construction of Italian society, from workers' rights to family law (Gandolfi and Pedrazzoli, 2009). In the vital and anarchic capital of the South, Naples, since 1999 La Scena delle Donne (from which the cultural association F.PL. Femminile Plurale ${ }^{66}$ derived) has been exploring the female universe through the performing arts, co-designing with local institutions participatory theatre experiences that have involved different female communities, from elderly women to housewives (Sapienza, 2016).

It is also worth mentioning non-academic dance, valued as one of the principal forms of body expression by the women's movement in its search for freedom and naturalness of the female body (Gandolfi, 2019). The Italian tradition of choreutic modernism was revived in the second half of the $20^{\text {th }}$ century by Anna Sagna and other female dancers, in an effort to transfer artistic research on corporeality to the world of amateur dance, and to dance with children and young people (Pontremoli, 2005; Fabris, 2015). These artists have become the protagonists of «a process of fluidification of social roles [that] brought them to recognise themselves with ever greater courage as cultural mediators» (Fabris, Pontremoli and Castellazzi, 2015, p. 80). Nowadays they build audience-engagement projects funded by public patrons aimed at the collective enjoyment of corporeality, at the awareness of the different ages of the female body, at its ironic and poetic choreutic expression ${ }^{67}$.

The last few decades have been marked by the transnational vitality of new feminist movements, some of which have strong theatrical and performative roots: for example, the militant commitment of Eve Ensler, the playwright of The Vagina Monologues (1996), inspired the V-Days movement and One Billion Rising, thus transforming the International Women's Day celebrations into protest mobilisations (Sauvage, 2008). Thanks to this and other movements (from Me Too to No Una Menos) a clear awareness of the greatest violence exerted on women by the patriarchal system has emerged in the national and international public discourse: that is, the social scourge of feminicides. The political agendas of many countries today make it the object of their intervention, often using applied theatre to build a new cultural and social awareness. The educational, social and healthcare agencies in Italy support training aimed at the younger generations, at social and healthcare

\footnotetext{
${ }^{66} \mathrm{https}: / /$ effepielle.wordpress.com/

${ }^{67}$ Just think, by way of example, of the playful workshops proposed by Silvia Gribaudi, (http://www.silviagribaudi.com/category/works/) over60_projects and What age are you acting?, or of the way in which in Turin La Lavanderia a Vapore, a Piedmontese Residency Centre for Dance, builds lively audience-engagement and territorial welfare projects based on community dance experiences (https://www.lavanderiaavapore.eu/innovazione-e-ricerca/).
} 
personnel, at men and women involved in gender violence through workshops based on role-playing, co-construction of imaginary situations, and other theatrical games to develop the participants' reflexivity, sensitivity, awareness and responsiveness. They adopt many different techniques, from Moreno's psychodrama and sociodrama to social theatre, but predominantly they refer to the methods of the Theatre of the Oppressed, thanks to a nationwide network of specialised theatre associations which follow Augusto Boal's methods (and apply them not only on this specific theme but also on other areas of social intervention through theatre).

Dealing with theatre as a tool for the empowerment of collective subjects, it is necessary to mention at least one other area that has been widely practiced in Italy for the last fifty years: that of Theatre in Prison, which is highly applied both in the female and male branches of correctional institutions. It is a vast array of practices which, as Claudio Meldolesi wrote twenty-five years ago in his enlightening contribution, Immaginazione contro emarginazione (imagination against exclusion) (1994, p. 41), continues to raise «civil issues such as the dignity of the inmates, their right to create» and which, unlike the women's scene, is widely documented through studies, reports and analyses, often commissioned and produced by public institutions (see the annual publications of the Coordinamento Teatro Carcere of the Emilia Romagna Region, Valenti, 2013). Thanks to the basic device of theatre play - discovering oneself by discovering others - theatrical workshops in prison generate social interaction and this aspect is central to the Italian applications of Theatre in prison, involving the inmates in workshops together with members of their families, with prison workers, with students, with volunteers from the community... In the last decade, stable networks have been built up, such as the National Coordination of Theatre and Prison and, on a regional basis, the Prison Theatre Coordination of the Region of Tuscany and the Region of Emilia-Romagna, funded and supported by the regional institutions who recognise their social value. In other cases, as in Lombardy, it is the universities that have built the theatrical dialogue between prisoners and civic society, with very interesting results (Innocenti Malini, 2011b). A rich live documentation in Theatre in Prison can be found on the Italian magazine Teatri della diversità, which has been documenting since 1996 several projects of applied theatre, narrating its deeds in fighting stereotypes and creating inclusion and relationships with disadvantaged sections of the population.

It seems appropriate to conclude this essay with a reference to Augusto Boal's latest volume, A estetica do oprimido (2009). Boal insists on the theatre as a critical and imaginative exercise of citizenship, and urges the 
active role of spect-actors and the democratisation of the aesthetic process, aiming to establish a vision valid for the whole spectrum of socially engaged theatre:

When those who do not belong to the artistic monarchy, ordinary individuals, are offered the possibility to realise an aesthetic process and to make art, from which they have been estranged and alienated, their atrophied expressive possibilities are amplified, their perception of the world is deepened, their desire to transform it is set in motion (Boal, [2009] 2011, p. $\left.98^{68}\right)$.

Thus interpreted and practised, the aesthetics and ethics of participatory theatres make the Brechtian perspective of the theatre relevant to today as a testing ground for the transformability and adaptability of hegemonic social and political structures: the perspective of theatre as a tool, at the service of emancipatory policies.

68 Translator's note: translated from Italian edition as this passage is missing in the English edition (although present in the original Spanish edition). 